\title{
The Effect of Environmental Conditions on the Motility of Escherichia coli
}

\author{
By J. ADLER AND BONNIE TEMPLETON \\ Departments of Biochemistry and Genetics, University of Wisconsin, \\ Madison, Wisconsin, U.S.A.
}

(Accepted for publication 24 August 1966)

SUMMARY

A simple chemically defined medium for examining the motility of Escherichia coli $\mathrm{K} 12$ was designed. The essential components were: (1) a chelating agent to protect the motility against inhibition by traces of heavy metal ions; (2) a buffer to keep the $\mathrm{pH}$ value at the optimum between $\mathrm{pH} 6.0$ and $7 \cdot 5 ;(3)$ an energy source to stimulate the motility above that allowed by an endogenous energy source. Oxygen was required unless an energy source was provided which yielded energy anaerobically. A temperature optimum was determined.

A chemically defined growth medium capable of producing motile bacteria was devised. It was found that the presence of glucose or growth above $37^{\circ}$ prevented synthesis of flagella.

\section{INTRODUCTION}

For many studies of bacterial motility, it would be desirable to work with chemically defined media and to know the effect of commonly encountered variables. The present work aimed to meet the following objectives. (a) To design for studying motility a medium which contained only known chemicals and which did not allow growth. (b) To determine the optimal conditions for motility in this medium, including the effects of $\mathrm{pH}$ value, temperature, ionic strength and the concentration of oxygen. (c) To find a chemically defined growth medium and suitable growth conditions for producing motile bacteria.

Escherichia coli was chosen because the vast knowledge of its biochemistry and genetics should be applicable to the study of numerous problems of bacterial motility. Many strains of $E$. coli are motile by virtue of having several flagella distributed around the cell.

To make the necessary measurements of motility, an assay described in the preceding paper by Adler \& Dahl (1967) was used. By omitting methionine from the medium, it was possible to study motility in the absence of chemotaxis.

\section{METHODS}

The strain в 275 of Escherichia coli was the same as that described by Adler \& Dahl (1967); this strain is $\mathrm{F}^{-}$, threonine-, leucine ${ }^{-}$, methionine - , lactose ${ }^{-}$, phosphataselysogenic for $\lambda$, resistant to $\lambda$ and $\mathrm{T} 1$, streptomycin-resistant and motile. The bacteria 
were grown in a growth medium containing the 20 amino acids commonly encountered in proteins, as described by Adler \& Dahl (1967), except where otherwise mentioned.

The medium for washing the bacteria free of growth medium, for studying motility, and for filling the capillary tubes contained $1 \times 10^{-2} \mathrm{M}$-potassium phosphate buffer $\left(\mathrm{pH} \mathrm{7.0)}\right.$ and $1 \times 10^{-4} \mathrm{M}$-EDTA. Various additions, such as an energy source, were made, as described in the text. Glass-distilled water was used for making solutions for this medium. Solutions of all organic components were sterilized by filtration. Since the leucine, methionine, and threonine required for growth were omitted, this motility medium did not sustain growth.

Capillary tubes were filled with this motility medium, inoculated at one end (the origin) with about $10^{6}$ Escherichia coli organisms and then closed off at both ends with agar plugs and at one end with clay, according to the procedure of Adler \& Dahl (1967). After incubation horizontally at $35^{\circ}$, the tubes were fractionated into ten compartments each $8 \mathrm{~mm}$. long by breaking the end away from the origin at the liquid/ agar junction and then withdrawing samples with a smaller capillary tube. Each sample was placed into EMB glucose streptomycin broth. The presence or absence of turbidity after $28 \mathrm{hr}$ incubation told whether or not the compartment contained viable bacteria. Usually there was turbidity in every tube from the origin to a certain point, but sometimes at the end away from the origin there was a skip which must have been due to an especially lucky or fast bacterium. A convention of not scoring these skips was adopted. Non-motile bacteria remained at the origin even after many hours of incubation. This assay locates the point of furthest advance of the bacteria-the frontier of the migration. Results which differ by one or even two compartments $(0.8$ or $1.6 \mathrm{~cm}$.) are not regarded as significantly different in this assay. The main reason for a considerable amount of variability is that a statistically small number of bacteriaeven one-can determine the location of the frontier.

\section{RESULTS}

\section{A motility medium and optimal conditions for motility}

Peptone or other such complex media have usually been used in the study of motility because these media allow excellent movement. The present aim was to determine which components of peptone are essential for motility. Table 1 shows that peptone could be completely replaced by a mixture of the 20 amino acids normally found in proteins, or even by a single amino acid such as L-glutamine or (not shown in the table) nearly any other of the amino acids. Surprisingly, however, glucose did not support motility (Table 1).

The effect of a chelating agent. The explanation for the phenomenon that amino acids supported motility but glucose did not, is the following; motility is highly sensitive to inhibition by trace amounts of heavy metal ions and amino acids are good chelating agents for metal ions while glucose chelates very poorly at neutral pH (Greenberg, 1951; Martel \& Calvin, 1952). The following experiments supported this explanation.

A chelating agent such as ethylenediaminetetraacetic acid (EDTA) added with glucose and buffer allowed excellent motility (Fig. 1). Maximum stimulation was obtained at $1 \times 10^{-6} \mathrm{M}$-EDTA and above (Fig. 2). Inhibition of motility began to appear 


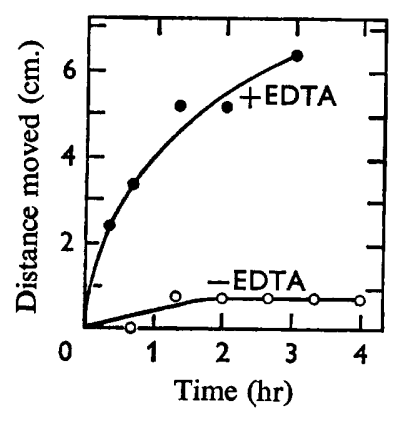

Fig. 1

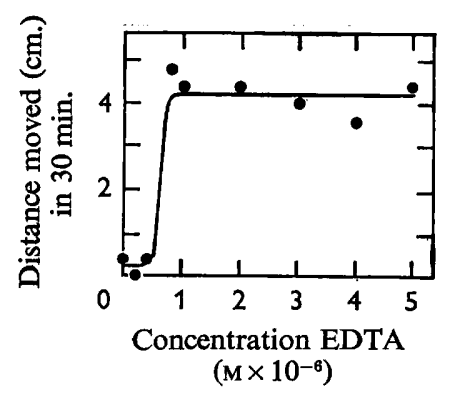

Fig. 2

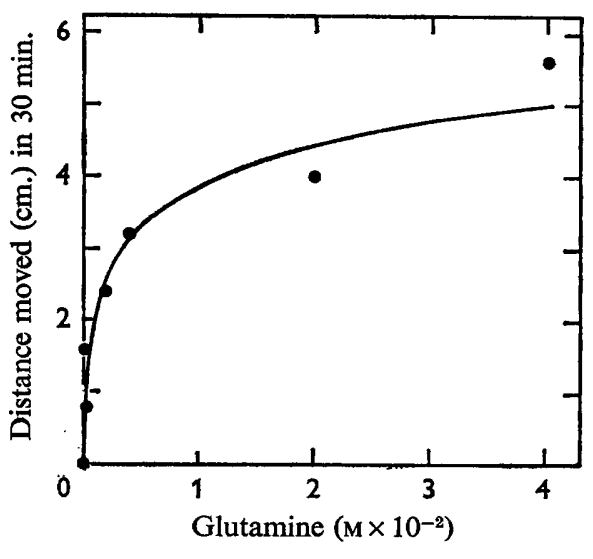

Fig. 3

Fig. 1. The effect of EDTA on motility of Escherichia coli. This and subsequent figures plot the point of furthest advance of the bacteria - the frontier of migration. A zero time blank of $1.6 \mathrm{~cm}$. was subtracted from all values in every figure. The farthest movement physically possible was $6.4 \mathrm{~cm}$. in the arrangement used in all the experiments reported in this paper. Phosphate buffer (pH 7.0;1 $\left.1 \times 10^{-2} \mathrm{M}\right)$, glucose $\left(1 \times 10^{-2} \mathrm{M}\right)$ and EDTA $\left(1 \times 10^{-4} \mathrm{M}\right)$ were present. In this experiment the tube was fractionated into twenty $0.4 \mathrm{~cm}$. compartments.

Fig. 2. The effect of EDTA concentration on motility of Escherichia coli. Phosphate buffer (pH $\left.7.0 ; 10^{-2} \mathrm{M}\right)$ and glucose $\left(10^{-2} \mathrm{M}\right)$ were present. In this experiment the tube was fractionated into twenty $0.4 \mathrm{~cm}$. compartments.

Fig. 3. The effect of glutamine concentration on motility of Escherichia coli. Phosphate buffer $\left(\mathrm{pH} 7.0 ; 10^{-2} \mathrm{M}\right)$ and glucose $\left(10^{-2} \mathrm{M}\right)$ were present; no EDTA.

Table 1. Replacement of peptone by a simpler motility medium for Escherichia coli

The components listed were added at a final concentration of $0.5 \%$. In each case $1 \times 10^{-2}$ M-potassium phosphate ( $\mathrm{pH} \mathrm{7.0)}$ was also present.

This and subsequent tables report the point of furthest advance of the bacteria-the frontier of the migration. For details see Methods. A blank of $1.6 \mathrm{~cm}$. has been subtracted from all values in every table, since at zero time the first two compartments were occupied.

Distance moved (cm.)

$\begin{array}{lll}\text { Peptone } & 1 \cdot 6 & 4 \cdot 0 \\ \text { Mixture of 20 amino acids } & 2 \cdot 4 & 4 \cdot 0 \\ \text { L-glutamine } & 2 \cdot 4 & 4 \cdot 8 \\ \text { L-glutamine + peptone } & 2 \cdot 4 & 4 \cdot 0 \\ \text { D-glucose } & 0 & 0\end{array}$

at $5 \times 10^{-2}$ M-EDTA. The position of the curve of Fig. 2 would depend on the content of inhibitory metal ions in the particular supply of water and other reagents used.

Glutamine stimulated motility in the presence of glucose and buffer (Fig. 3), but the concentration required for maximum"stimulation was"much higher for glutamine (about $2 \times 10^{-2} \mathrm{M}$ ) than for EDTA, presumably because glutamine is not as effective a chelating agent. In the presence of $2 \times 10^{-2} \mathrm{M}$-glutamine, EDTA did not stimulate further. Besides glutamine, several other materials known to have chelating ability also stimulated motility; this list includes peptone, albumin, citrate, oxalate, iminodi- 
acetic acid, mercaptoethanol, nearly all of the L-amino acids, D-serine, D-threonine and D-glutamine.

Bacteria which were highly motile completely lost their motility within $30 \mathrm{~min}$. when they were washed free from medium and then placed into a medium lacking a chelating agent. The motility was fully restored at once by adding EDTA or amino acids, even $2 \mathrm{hr}$ after movement had first stopped. This result showed that the inhibition of motility by metal ions was reversible.

A medium inhibitory of motility, such as glucose + phosphate buffer, that was first passed through a chelating resin (Dowex A 1, also called Chelex 100, which has iminodiacetic acid covalently bound) to remove metal ions, allowed excellent motility even in the absence of any added chelating agent (line 1 of Table 2). Such chelating-resintreated medium served for measuring the effect of a large number of metal ions on motility. In this way copper ion, a common contaminant of water and reagents, was shown to be a potent inhibitor (Table 2); $\mathrm{AgCl}$ and $\mathrm{HgCl}_{2}$ also inhibited at nearly as low concentrations.

\section{Table 2. The effect of cupric chloride on motility of Escherichia coli}

The motility medium, containing $10^{-2} \mathrm{M}$-glucose and $10^{-2} \mathrm{M}-\mathrm{phosph}$ ate buffer $(\mathrm{pH} 7 \cdot 0$ ), was first passed through Dowex A 1 chelating resin to allow examination of motility in the absence of a chelating agent.

$\begin{array}{ccc}\begin{array}{c}\text { Concentration of } \\ \mathrm{CuCl}_{2}(\mathrm{M})\end{array} & \begin{array}{c}\text { Distance moved in } \\ 4 \mathrm{hr}(\mathrm{cm} .)\end{array} & \begin{array}{c}\text { No. of bacteria viable } \\ \text { at } 4 \mathrm{hr}\end{array} \\ 0 & 6 \cdot 4 & 2.4 \times 10^{8} \\ 10^{-8} & 3 \cdot 2 & 4.7 \times 10^{6} \\ 10^{-7} & 1 \cdot 6 & 2.2 \times 10^{6} \\ 10^{-6} & 0 & 1 \cdot 7 \times 10^{6} \\ 10^{-5} & 0 & 0\end{array}$

At much higher concentrations, most metal ions inhibited motility. At $10^{-5} \mathrm{M}$ inhibition appeared with $\mathrm{BaCl}_{2}, \mathrm{CdCl}_{2}, \mathrm{CoCl}_{2}$ and $\mathrm{NiCl}_{2}$; at $10^{-3} \mathrm{M}$ inhibition by $\mathrm{CaCl}_{2}, \mathrm{MgCl}_{2}, \mathrm{MnCl}_{2}$ and $\mathrm{ZnCl}_{2}$ appeared. There was no inhibition by $\mathrm{PbCl}_{2}, \mathrm{Na}_{2} \mathrm{~B}_{4} \mathrm{O}_{7}$ or $\mathrm{Na}_{2} \mathrm{MoO}_{4}$ at $10^{-4} \mathrm{M}$, and a stimulation at that concentration was produced by $\mathrm{Al}_{2}\left(\mathrm{SO}_{4}\right)_{3}, \mathrm{CrCl}_{3}, \mathrm{Fe}_{2}\left(\mathrm{SO}_{4}\right)_{3}$ and $\mathrm{SnCl}_{4}$.

Even though first treated with a chelating resin, $\mathrm{NaCl}, \mathrm{KCl}$, and $\mathrm{NH}_{4} \mathrm{Cl}$ were somewhat inhibitory at $10^{-2} \mathrm{M}$, and more so at $10^{-1} \mathrm{M}$; the $\mathrm{Cl}^{-}$or $\mathrm{NO}_{3}^{-}$salts tended to be less inhibitory than $\mathrm{SO}_{4}^{2-}$ salts. Potassium phosphate buffer $\left(\mathrm{pH} \mathrm{7.0)}\right.$ at $10^{-1} \mathrm{M}$ partially inhibited, even though first treated with chelating resin. It is clear from this information that high ionic strengths inhibited motility and should be avoided when optimum motility is desired.

The effect of an energy source. Motility was observed in the absence of any added energy source, although the addition of a chelating agent such as EDTA was necessary to demonstrate it (lines 1 and 2 of Table 3). This motility must have been due to an endogenous energy source, since after three extra washes to remove contaminating growth medium (by alternate centrifugation and resuspension of the bacteria) there was still good motility (Table 3). For further evidence see the discussion about galactose in the next section. The addition of an energy source such as glucose or glutamine did, however, stimulate the rate of movement (Table 3).

The effect of oxygen. The following experiments show that glutamine could serve 
as an energy source for motility only when oxygen was available. A suspension of motile Escherichia coli in L-glutamine +EDTA + phosphate buffer $(\mathrm{pH} 7 \cdot 0)$ remained motile for days in a hanging drop on a slide, as judged by microscopic examination. However, when a coverslip, surrounded by stopcock grease to prevent evaporation, was placed on a drop, the motility came to a stop within 10 or 20 min., except near air bubbles. Removal of the coverslip, even 2 days after movement had stopped, resulted in immediate restoration of motility. This cessation of movement in presence of glutamine under a coverslip was fully prevented by including Chlorella algae with the bacteria and shining light on the suspension; the motility of the bacteria could be turned on or off at will by removing or inserting a green filter in the light path. The motility in the presence of Chlorella and light, which persisted for at least 3 days, presumably was due to a supply of oxygen generated by the photo-synthetic algae. The results confirm similar studies reported by Engelmann in 1881 (for a review see Weibull, 1960).

\section{Table 3. Effect of energy source on motility of Escherichia coli}

In the first experiment, the bacteria were washed free from growth medium twice as usual (Adler \& Dahl, 1967). In the second experiment, the bacteria were washed an additional two times. When this was followed by still another wash, exactly the same data as in Expt. 2 were obtained. Phosphate buffer $\left(\mathrm{pH} 7 \cdot 0,10^{-2} \mathrm{M}\right)$ and EDTA $\left(10^{-4} \mathrm{M}\right)$ were present. Glucose or glutamine was added to $10^{-2} \mathrm{M}$.

$\begin{array}{clc}\text { Expt. no. } & \text { Energy source added } & \begin{array}{c}\text { Distance moved } \\ \text { in } 30 \mathrm{~min} .(\mathrm{cm} .)\end{array} \\ 1 & \text { None } & 2.4 \\ & \text { None; EDTA omitted } & 0 \\ & \text { Glucose } & 5.6 \\ & \text { Glutamine } & 5.6 \\ 2 & \text { None } & 1.6 \\ & \text { Glutamine } & 4.8\end{array}$

With tryptone or a mixture of the 20 amino acids commonly found in proteins, Escherichia coli grown aerobically on a mixture of the 20 amino acids (Adler \& Dahl 1967) remained weakly motile under a coverslip for at least a day, in contrast to its behaviour with glutamine. Each of the amino acids in this mixture was tested singly to determine which were responsible for this anaerobic movement. Only L-serine allowed movement to continue under a coverslip; this anaerobic motility on L-serine persisted for many hours, but it was not as vigorous as when the coverslip was removed. A direct demonstration that serine can be consumed both aerobically and anaerobically is presented elsewhere (Adler, 1966). E. coli contains L-serine dehydrase (Wood \& Gunsalus, 1949; Pardee \& Prestidge, 1955; Umbarger \& Brown, 1957), an enzyme which can catalyse the anaerobic conversion of L-serine to pyruvate; the pyruvate can then be dismutated anaerobically to yield energy. As expected from this, pyruvate allowed good movement for many hours under a coverslip. Also glucose allowed such anaerobic movement for 2 days, although again the movement was more vigorous without the coverslip, presumably because the supply of energy is more abundant aerobically than anaerobically.

Escherichia coli grown anaerobically on a mixture of the 20 amino acids were motile anaerobically on L-threonine and L-tryptophan, as well as on L-serine. Anaerobic 
conditions induce L-threonine dehydrase (Wood \& Gunsalus, 1949; Umbarger \& Brown, 1957) and apparently also tryptophanase.

On D-serine there was anaerobic movement for many hours, but only when the bacteria were first grown in the presence of D-serine; Escherichia coli is known to contain a D-serine dehydrase inducible by D-serine (Pardee \& Prestidge, 1955).

Without any added energy source, extensively washed Escherichia coli were motile in a hanging drop containing EDTA + phosphate buffer, but the movement under a coverslip quickly stopped. This showed that the endogenous energy source required oxygen for its utilization. Even when the bacteria were grown on galactose, swimming of the washed bacteria stopped under anaerobic conditions. Since galactose allowed both aerobic and anaerobic motility, this is additional evidence that the endogenous energy source is not some residual energy source from the medium.

Salmonella abortusequi, strain NCTC 5727, grown aerobically on a mixture of 20 amino acids, remained motile under a coverslip for a day or more on tryptone or on a mixture of 20 amino acids. Each amino acid was tested singly and the support of motility was traced to L-serine and L-threonine; presumably these bacteria contain an L-serine dehydrase and L-threonine dehydrase. Sherris, Preston \& Shoesmith (1957) reported that Pseudomonas viscosa required oxygen for movement except in the presence of arginine, and that this strain could metabolize arginine anaerobically to yield adenosine triphosphate. Different strains and species of bacteria may be able to swim anaerobically on different substrates, depending on the repertoire of enzymes available for yielding energy anaerobically. In fact, this test for anaerobic motility would seem to be a rapid, effective technique for learning about the anaerobic metabolism of motile bacteria.

The conclusion from this study is that motility requires oxygen if the particular substrate yields energy only aerobically, but motility does not require oxygen if pathways are present for obtaining energy from a substrate anaerobically. Even when a substrate can yield energy anaerobically, the aerobic motility on that substrate is more vigorous, presumably because the aerobic production of energy is more abundant.

The effect of $\mathrm{pH}$ value. The optimum $\mathrm{pH}$ value for motility was between $\mathrm{pH} 6$ and 7.5 (Fig. 4). Cacodylate (not shown in Fig. 4) or tris could replace phosphate buffer, so there was no requirement for added phosphate in this system. The shape of the $\mathrm{pH}$ curve must be determined by the effect of $\mathrm{pH}$ value on energy generation and perhaps other processes, as well as on motility. Flagella are known to disintegrate into subunits at pH 3-4 (Weibull, 1948; Stocker \& Campbell, 1959).

The effect of temperature. Figure 5 shows that the optimum temperature for motility was about $25-37^{\circ}$. This optimum applies only to the particular time of incubation (30 min.) used here. A detailed study of the effect of temperature on the motility of Salmonella by Ogiuti (1936) showed that the optimum temperature decreased as the incubation time increased.

\section{A growth medium for producing motile Escherichia coli and the effect of growth conditions}

Ordinarily peptone or other such complex media have been used to grow bacteria that are highly motile. The present aim was to find a medium that was chemically defined and still produced Escherichia coli capable of excellent movement in the motility medium. It was found that peptone could be replaced by inorganic salts and a mixture 
of 20 amino acids. This growth medium (Adler \& Dahl, 1967) was used in all of the experiments mentioned up to this point.

The effect of glucose in the growth medium. When glucose replaced the mixture of 20 amino acids in the growth medium (except that leucine, methionine and threonine, which are necessary for the growth of this strain of Escherichia coli, were added) surprisingly the migration of organisms grown in this way was very slow and did not proceed far in capillary tubes containing glucose + EDTA + phosphate buffer ( $\mathrm{pH} 7 \cdot 0)$ (bottom curve of Fig. 6). Even when a chelating agent (e.g. citrate) was present in the glucose-containing growth medium, and even though the $\mathrm{pH}$ value of the growth medium remained near $\mathrm{pH} 7 \cdot 0$, about $99 \%$ of these bacteria were not motile, as judged by microscopic examination. The explanation for this lack of motility of the vast majority of these bacteria grown in presence of glucose was that these bacteria lacked flagella. Plate 1 compares bacteria grown in the presence of the 20 amino acids (fig. 1) with bacteria grown in the same medium except that glucose (and a supplement of leucine, methionine, and threonine) replaced the amino acid mixture (fig. 2). Bacteria grown in the presence of the amino acid mixture had numerous flagella, while those grown in the presence of glucose for the most part had no flagella,

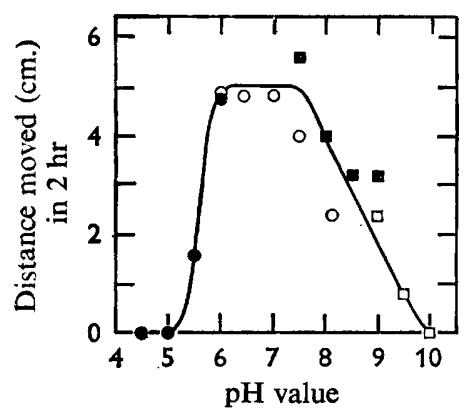

Fig. 4

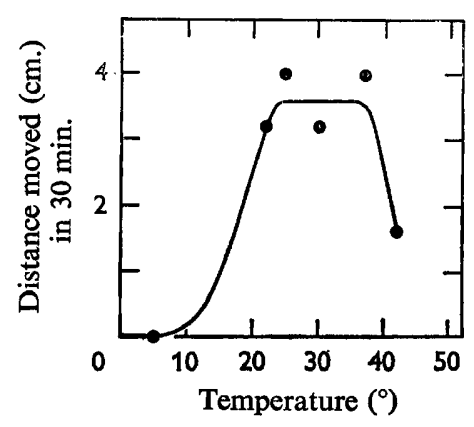

Fig. 5

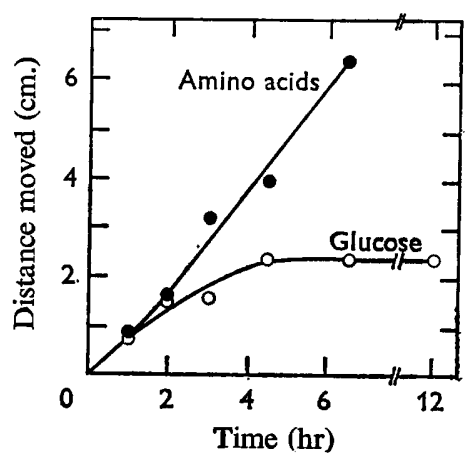

Fig. 6

Fig. 4. The effect of $\mathrm{pH}$ value on motility of Escherichia coli. - - , potassium acetate buffer; $\bigcirc-O$, potassium phosphate buffer; $\square-\square$, tris hydrochloride buffer; $\square-\square, \beta$-alanine buffer. EDTA $\left(10^{-4} \mathrm{M}\right)$ was present. No energy source was added; in the absence of an added fermentable energy source, motility stopped when the oxygen was used up. The observed motility was therefore due to those bacteria which migrated from the crowded oxygendeficient region at the origin. Complete loss of viability in $2 \mathrm{hr}$ occurred when more extreme $\mathrm{pH}$ values $(\mathrm{pH}<4.0$ and $>10.5)$ than those reported in the figure were used.

Fig. 5. The effect of temperature on motility of Escherichia coli. Phosphate buffer $(\mathrm{pH} 7 \cdot 0$, $\left.10^{-2} \mathrm{M}\right)$, glutamine $\left(10^{-2} \mathrm{M}\right)$ and EDTA $\left(10^{-4} \mathrm{M}\right)$ were present. Since glutamine was not fermentable, motility stopped when the oxygen was used up. The observed motility was therefore due to those bacteria which migrated from the crowded oxygen-deficient region at the origin.

Fig. 6. The effect of amino acids on the motility of Escherichia coli grown on glucose. The cells were grown in the growth medium described in the preceding paper (Adler \& Dahl, 1967), except that the mixture of 20 amino acids was replaced by glucose ( $5 \mathrm{~g} . / 1$. medium) and a supplement of leucine, methionine and threonine $(250 \mathrm{mg}$. each/l. medium). The bacteria were then washed free of this medium and placed into motility medium. In the bottom curve, the motility medium contained glucose $\left(1 \times 10^{-2} \mathrm{M}\right)$, phosphate buffer $\left(\mathrm{pH} 7 \cdot 0 ; 1 \times 10^{-2} \mathrm{M}\right)$ and EDTA $\left(1 \times 10^{-4} \mathrm{M}\right)$. In the top curve, a mixture of the 20 amino acids normally found in proteins (each at about $1 \times 10^{-3} \mathrm{M}$ ) replaced glucose in the motility medium. 
sometimes one short flagellum, and very rarely $(0 \cdot 1-1 \%)$ a normal complement of flagella. This conclusion was confirmed by the following two independent tests.

Escherichia coli grown in the presence of the amino acid mixture agglutinated when anti-flagella serum was added while glucose-grown bacteria did not agglutinate. (The antiserum was prepared and kindly given to us by M. L. DePamphilis.) In addition, the bacteria grown on the amino acid mixture readily adsorbed $\chi$, a phage that attacks only flagellated bacteria (Meynell, 1961), while the bacteria grown on glucose adsorbed phage $\chi$ at a just barely detectable rate (S. Z. Schade, unpublished).

Motile Escherichia coli organisms grown in medium containing the 20 amino acids were non-motile and lacked flagella beginning at about 6 divisions after they were transferred into a medium containing glucose instead of the amino acids (or even glucose in addition to the amino acids). Bacteria grown for as many as 20 divisions in the presence of glucose quickly regenerated flagella when placed into a medium free from glucose and containing the 20 amino acids. This restored motility, as shown in the top curve of Fig. 6. Omission of leucine, methionine and threonine from this mixture of amino acids prevented restoration of motility, presumably because this strain is unable to synthesize the protein of flagella without these amino acids which are required for growth. It is clear that glucose shut off the synthesis of flagella and that this effect was annulled by removal of the glucose. It was possible in this way to go back and forth between flagellate and largely non-flagellate phases.

Lactate behaved like glucose in stopping synthesis of flagella, but the following carbon sources when replacing the amino acid mixture in the growth medium produced normally motile bacteria with normal flagella: galactose, glycerol, succinate, $\alpha$-ketoglutarate. The inhibitory effect of glucose on the synthesis of flagella was also shown, though to a very much lesser degree, with another strain of Escherichia coli, w 3110; but the motility and flagellation of Salmonella typhimurium, strain TM2, was not affected by glucose in the growth medium, even after 25 divisions.

The effect of $\mathrm{pH}$ value of growth, temperature of growth and age of culture. Escherichia coli was adapted for at least eight divisions to grow at values ranging between $\mathrm{pH} 6.0$ and 8.0 in the medium described under Methods. The bacteria grown at each $\mathrm{pH}$ value were normally motile and had a normal complement of flagella. Therefore, variation in the $\mathrm{pH}$ value of growth within the range $\mathrm{pH} 6 \cdot 0-8 \cdot 0$ was not critical for studies of motility in this strain of $E$. coli.

The effect of temperature of growth was studied. Escherichia coli grown at $24^{\circ}$ was more motile than when grown at $37^{\circ}$, as judged by the motility assay. Organisms grown at $40^{\circ}$ or above were very weakly motile and had very few flagella, even though the growth rate was near normal. Such organisms were resistant to bacteriophage $\chi$ (S. Z. Schade, unpublished). It is clear that temperatures above $37^{\circ}$ should be avoided to get good synthesis of flagella; even $37^{\circ}$ is border-line. The inhibition of synthesis of flagella by elevated temperatures has been noted previously (Ogiuti, 1936, for E. coli; Meynell, 1961, and Quadling \& Stocker, 1962, for Salmonella).

Escherichia coli organisms harvested at various stages of growth were tested in the motility assay. It was found that organisms in the exponential phase were the most motile; these were used for all the studies reported here. Organisms from lag phase or from late stationary phase cultures were distinctly inferior for motility. 


\section{DISCUSSION}

The aim of developing a completely defined medium for the expression of motility led to the finding that heavy metal ions at very low concentrations inhibited the motility of Escherichia coli organisms, and that amino acids could stimulate motility by virtue of chelating these metals. Stocker \& Campbell (1959) and Meynell (1961) noted that Salmonellas washed in saline lost their motility and that the motility was regained when a complex broth, albumin, or an amino acid was added. Apparently no other study of the requirements for a chemically defined motility medium has been reported before for bacteria. Tyler (1953) and Rothschild \& Tyler (1954) showed that amino acids protected the motility and fertilizing ability of sea-urchin spermatozoa and that chelating agents could replace the amino acids. The mechanism by which heavy metal ions inhibit bacterial movement is not understood; it is not known whether metal ions inhibit the movement directly, or whether the effect on movement results indirectly from an inhibition of some other process-for example, production of adenosine triphosphate. The protective effect of chelating agents for the viability of bacteria has been generally recognized.

The results reported here show that it has been possible to replace a complex motility medium such as peptone with simply a chelating agent, an energy source and a buffer and still obtain excellent motility of Escherichia coli. By using a strain of bacteria which requires certain nutritional factors (in this particular case leucine, methionine, threonine) and not providing these factors in the motility medium, one can obtain motility without the complications of chemotaxis (Adler \& Dahl, 1967) or growth.

The attempt to devise a chemically defined growth medium for producing motile bacteria led to the observation that glucose prevented the synthesis of flagella. The mechanism of this effect of glucose remains unknown. The glucose effect has been commonly observed for many enzymes (see review by Magasanik, 1961), and the effect is now extended to include a structure or organelle-the flagellum. Apparently there are no other published studies on the requirements of a chemically defined growth medium for producing bacteria with high motility, although it has been noted that a defined medium may lead to synthesis of fewer flagella (Kerridge, 1959).

For many helpful discussions we thank Drs H. Echols and H. M. Temin. Dr Temin called our attention to the work of Rothschild \& Tyler (1954) and suggested the use of EDTA and the idea that amino acids protect bacterial motility by chelation.

This research was supported by grants from the U.S. National Science Foundation, the National Institutes of Health, and the Graduate School of the University of Wisconsin.

The authors thank Dr J. L. Tschernitz for taking the photographs.

\section{REFERENCES}

ADLER, J. (1966). The effect of amino acids and oxygen on chemotaxis in Escherichia coli. J. Bact. 92, 121.

ADLER, J. \& DAHL, M. M. (1967). A method for measuring the motility of bacteria and for comparing random and non-random motility. J. gen. Microbiol. 46, 161.

Greenberg, D. M. (1951). Amino acids and Proteins, p. 465. Springfield, Illinois: C. C. Thomas.

KERRIDGE, D. (1959). Synthesis of flagella by amino acid-requiring mutants of Salmonella typhimurium. J. gen. Microbiol. 21, 168. 
LEIFSON, E. (1951). Staining, shape, and arrangement of bacterial flagella. J. Bact. $62,377$.

MagasaniK, B. (1961). Catabolite repression. Cold Spr. Harb. Symp. quant. Biol. 26, 249.

Martell, A. E. \& Calvin, M. (1952). Chemistry of the Metal Chelate Compounds. New York; Prentice-Hall, Inc.

MeYNELL, E. W. (1961). A phage, $\Phi \chi$, which attacks motile bacteria. J. gen. Microbiol. $25,253$.

OGIUTI, K. (1936). Untersuchungen über die Geschwindigkeit der Eigenbewegung von Bakterien. Jap. J. exp. Med. 14, 19.

PARDeE, A. B. \& Prestidge, L. S. (1955). Induced formation of serine and threonine deaminases by Escherichia coli. J. Bact. 70, 667.

Quadling, C. \& STocker, B. A. D. (1962). An environmentally induced transition from the flagellated to the non-flagellated state in Salmonella typhimurium: the fate of parental flagella at cell division. J. gen. Microbiol. 28, 257.

ROTHSCHILD, LORD \& TYLER, A. (1954). The physiology of sea-urchin spermatozoa; action of versene. J. exp. Biol. 31, 252.

Sherris, J. C., Preston, N. W. \& Shoesmith, J. G. (1957). The influence of oxygen and arginine on the motility of a strain of Pseudomonas sp. J. gen. Microbiol. 16, 86.

Stocker, B. A. D. \& CAMpbell, J. C. (1959). The effect of non-lethal deflagellation on bacterial motility and observations on flagellar regeneration. J. gen. Microbiol. 20, 670.

TyLER, A. (1953). Prolongation of life-span of sea urchin spermatozoa. Biol. Bull. mar. biol. Lab., Woods Hole 104, 224.

UMBarger, H. E. \& Brown, B. (1957). Threonine deamination in Escherichia coli. II. Evidence for two L-threonine deaminases. J. Bact. 73, 105.

WeIBull, C. (1948). Some chemical and physico-chemical properties of the flagella of Proteus vulgaris. Biochim. biophys. Acta 2, 351.

Weibull, C. (1960). Movement. In The Bacteria. Ed. by I. C. Gunsalus and R. Y. Stanier, vol. I, p. 153. New York: Academic Press.

Wood, W. A. \& Gunsalus, I. C. (1949). Serine and threonine deaminases of Escherichia coli: activators for a cell-free enzyme. J. biol. Chem. 181, 171.

\section{EXPLANATION OF PLATE}

The effect of carbon source on the synthesis of flagella by Escherichia coli.

Fig. 1. Escherichia coli grown in the growth medium of Adler \& Dahl (1967) which contains a mixture of 20 amino acids.

Fig. 2. The amino acid mixture of the growth medium was replaced by glucose $(5 \mathrm{~g} . / 1$.) and a supplement of leucine, methionine and threonine (each $250 \mathrm{mg} . / 1$.$) ; in this picture several bacteria each$ with only one flagellum may be seen. The flagella were stained according to Leifson (1951). 


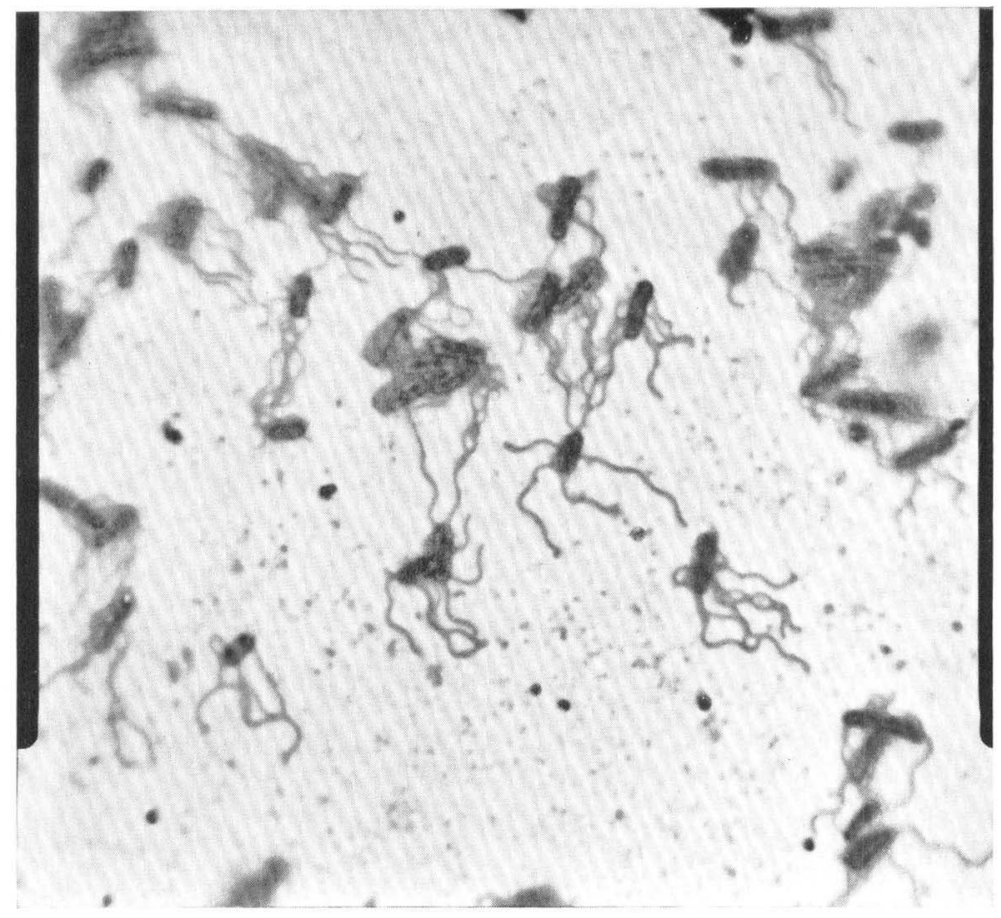

Fig. 1

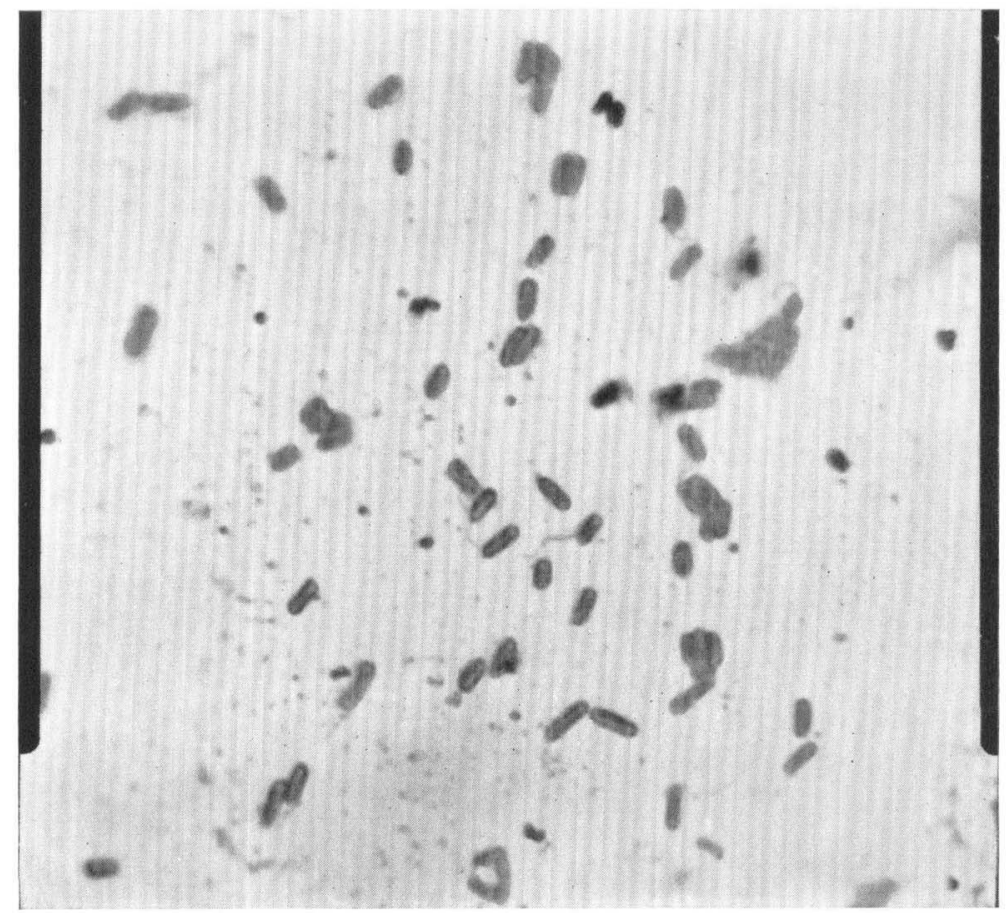

Fig. 2 